\title{
PENGEMBANGAN MEDIA PEMBELAJARAN MATEMATIKA MENGGUNAKAN GEOGEBRA DAN MICROSOFT MATHEMATIC DI LA ROYBA ISLAMIC SCHOOL
}

\author{
Cynthia Rahmawati \\ cynthiarahma23@gmail.com
}

\begin{abstract}
One of the learning media that suits the current development especially in learning in the field of mathematics is the use of software. Usefulness of software can help teachers to deliver abstract mathematical material becomes more easily understood because the software can visualize learning in that field. In addition, Geogebra and Microsoft Mathematic are designed to train the ability independently in the creativity and critical power of students. This study aims to develop learning media through software Geogebra and Microsoft Mathematic on junior high and high school materials at La Royba Islamic School. The results obtained are GeoGebra and Microsoft Math can be used as a medium of learning in math and can be downloaded for free, so it is easy to get it. Based on the research also, the student activity using the geogebra software and Microsoft math experienced a change toward a better attitude. This change starts from the student's attitude enough, good enough, and good to the development of learning media of mathematics using geogebra and Microsoft math. In addition, with the features and ease of existing applications in both this software can help teachers in delivering learning materials, so that students can be actively involved independently and make learning more creative, effective and meaningful. Creativity is honed to students may also increase the creativity of students with an understanding that can create their own mathematical problem solving in accordance with the wishes of students. Both of these software have special benefits with GeoGebra emphasizes on Geometry while Microsoft Math on Algebra or linear equations. Based on all this, it can be concluded that Geogebra and microsofth mathematic is feasible and can be used as a medium of learning.
\end{abstract}

Keywords: Learning Media, Mathematics, Geogebra, Microsoft Mathematic, La Royba Islamic School

\begin{abstract}
Abstrak
Salah satu media pembelajaran yang sesuai dengan perkembangan saat ini khususnya dalam pembelajaran di bidang matematika adalah penggunaan software. Kegunaan software dapat membantu guru untuk menyampaikan materi matematika yang abstrak menjadi lebih mudah dipahami karena software dapat memvisualkan pembelajaran di bidang tersebut. Selain itu, software Geogebra dan Microsoft mathematic dibuat untuk melatih kemampuan secara mandiri dalam daya kreativitas dan daya kritis siswa. Penelitian ini bertujuan untuk mengembangkan media pembelajaran melalui software program Geogebra dan Microsoft Mathematic pada materi SMP dan SMA di La Royba Islamic School. Hasil penelitian yang diperoleh yaitu Software GeoGebra dan Microsoft Math dapat digunakan sebagai media pembelajaran dalam matematika dan dapat diunduh secara gratis, sehingga mudah mendapatkannya. Berdasarkan penelitian juga, maka aktivitas siswa yang menggunakan software geogebra dan Microsoft math mengalami perubahan ke arah sikap yang lebih baik. Perubahan ini dimulai dari sikap siswa yang cukup, cukup baik, dan baik terhadap pengembangan media pembelajaran matematika menggunakan software geogebra dan Microsoft math. Selain itu, dengan adanya fitur-fitur dan kemudahan aplikasi yang ada pada kedua software ini dapat membantu guru dalam menyampaikan materi pembelajaran, sehingga siswa dapat terlibat aktif secara mandiri serta menjadikan pembelajaran lebih kreatif, efektif dan bermakna. Kreativitas yang diasah kepada siswa kemungkinan juga meningkatkan daya kreativitas siswa dengan pemahaman matematis yang dapat membuat sendiri penyelesaian permasalahan sesuai dengan keinginan siswa. Kedua software ini memiliki manfaat khusus denganGeoGebra menekankan pada Geometri sedangkan Microsoft Math pada Aljabar atau persamaan garis/linier. Berdasarkan semua ini, maka dapat disimpulkan bahwa media tersebut layak dan dapat digunakan sebagai media pembelajaran.
\end{abstract}

Kata kunci: Media Pembelajaran, Matematika, Geogebra, Microsoft Mathematic, La Royba Islamic School 


\section{PENDAHULUAN}

Salah satu kebijakan umum pembangunan pendidikan di Indonesia adalah peningkatan mutu pendidikan ${ }^{1}$. Pendidikan mempunyai tanggung jawab dalam mewujudkan sumber daya manusia yang berkualitas terutama mempersiapkan peserta didik sebagai penerus pembangunan masa depan yang kompeten, mandiri, kritis, kreatif serta sanggup menyelesaikan permasalahan yang mereka hadapi ${ }^{2}$. Selain itu, melalui pendidikan, manusia dapat mengembangkan potensi dirinya. Potensi diri tersebut dilakukan dengan pembentukan dan pengembagan kepribadian yang dapat dicapai mulai dari membaca, menulis hingga dapat menganalisis dalam bentuk pembelajaran ${ }^{3}$.

Potensi diri yang ada pada setiap manusia dalam dunia Pendidikan Indonesia secara peraturan Kementerian Pendidikan tertuang pada UU No. 20 Tahun 2003 pasal 1 dijelaskan bahwa potensi diri merupakan kemampuan, kekuatan, baik yang belum terwujud maupun yang telah terwujud, yang dimiliki seseorang, tetapi belum sepenuhnya terlihat atau dipergunakan secara maksimal. Dengan demikian, peserta didik

\footnotetext{
${ }^{1}$ Muljo Raharjo, Daryanto, Model Pembelajaran (Yogyakarta: Gava Media, 2012), h. 143.

${ }^{2}$ Yuliasari, E. Eksperimentasi Model PBL dan Model GDL Terhadap Kemampuan Pemecahan Masalah Matematis Ditinjau dari Kemandirian Belajar. (2017). JIPM (Jurnal IImiah Pendidikan Matematika), h. 6, 1-10.

${ }^{3}$ Anggoro, B. S. Pengembangan Modul Matematika Dengan Strategi Problem Solving untuk Mengukur Tingkat Kemampuan Berpikir Kreatif Matematis Siswa. (2015). Al-Jabar: Jurnal Pendidikan Matematika, h. 122-129.
}

yang dijelaskan dalam undang-undang harus selalu berusaha mengembangkan potensi diri melalui proses pembelajaran yang tersedia pada jalur, jenjang, dan jenis pendidikan tertentu. Proses pembelajaran yang baik berdasarkan kurikulum yang mengacu pada standar nasional pendidikan untuk mewujudkan tujuan pendidikan nasional. Satuan kurikulum belajar mengajar di Pendidikan Indonesia yang baik harusnya terbagi atas dua kurikulum yaitu kurikulum life skills dan academic. Setiap sekolah yang ada di Indonesia baik Negeri maupun Swasta seharusnya melakukan kegiatan dua kurikulum dengan seimbang, demi perbaikan generasi muda dengan potensi diri di bidang akademik maupun kebisaan dengan pembangunan karakter yang baik. Pengembangan dua kurikulum tersebut harus sangat didukung oleh sumber daya manusia yang ahli di bidangnya dan perkembangan teknologi yang mendukung, khususnya dalam pembelajaran bidang matematika. Karena tak bisa dipungkiri, kelanjutan dari pembelajaran matematika adalah pemahaman dan pemanfaatan bidang ini ke dalam dunia science and technology, terkhusus bidang teknologi informasi dan komputer.

Matematika merupakan mata pelajaran yang mengkaji sesuatu yang abstrak dalam permasalahan dan memerlukan daya berpikir logis untuk mencapai solusi dari persoalan/pernasalahan sehingga untuk menyampaikannya diperlukan suatu media agar siswa menjadi lebih memahami materi yang disampaikan dan merangsang siswa untuk meningkatkan kemampuan daya berpikir logis. Penggunaan software saat ini sebagai salah satu media pembelajaran yang sesuai dengan per- 
kembangan dunia. Keberadaan software dapat membantu guru untuk menyampaikan materi matematika yang abstrak menjadi lebih mudah dipahami karena software dapat memvisualkan hal itu. Selain itu, software yang dibuat sebagaian besar juga dibuat untuk melatih daya kreativitas dan daya kritis siswa ${ }^{4}$.

Matematika terdiri dari berbagai konsep yang tersusun secara hirarki, sehingga pemahaman konsep matematis menjadi sangat penting. Belajar konsep matematika merupakan hal yang paling mendasar dalam proses belajar matematika, oleh karena itu seorang guru dalam mengajarkan sebuah konsep, harus bertujuan pada sebuah tujuan yang harus dicapai. Hubert dan capenter (1992) menyatakan bahwa "salah satu ide yang diterima secara luas dalam pendidikan matematika, adalah bahwa siswa harus memahami matematika". Marpaung (2008) juga berpendapat bahwa matematika tidak akan ada artinya kalau hanya dihapalkan. National Council of Teachers of Mathematics (NCTM 2000) juga menyatakan bahwa tujuan umum pembelajaran matematika adalah siswa harus mempelajari matematika melalui pemahaman dan aktif membangun pengetahuan baru dari pengalaman dan pengetahuan sebelumnya ${ }^{5}$.

\footnotetext{
${ }^{4}$ Aminah Ekawati (2016). Penggunaan Software Geogebra dan Microsoft Mathematic dalam Pembelajaran Matetamatika. Jurnal Pendidikan Matematika Vol. 2, No. 3, September-Desember 2016. STKIP PGRI Banjarmasin.
}

${ }^{5} J a c k s o n$ Pasini Mairing (2013). Pembelajaran dengan Komputer: Dua Sisi Mata Uang. Makalah dalam Seminar Nasional Matematika dan Pendidikan Matematika FMIPA UNY. Prodi
Berdasarkan penelitian sebelumnya diketahui bahwa penggunaan aplikasi geogebra di SMKN 6 Bandung, Universitas Pasundan, 2015 diperoleh hasil penelitian yaitu: 1) Peningkatan kemampuan pemahaman matematis siswa yang memperoleh model PBL menggunakan Geogebra lebih baik dari siswa yang memperoleh Model PBL. 2) Peningkatan kemampuan pemahaman matematis siswa yang memperoleh model PBL menggunakan Geogebra lebih baik dari siswa yang memperoleh pembelajaran konvensional. 3) Peningkatan kemampuan pemahaman matematis siswa yang memperoleh model PBL lebih baik dari siswa yang memperoleh pembelajaran konvensional. 4) Kemandirian belajar siswa yang memperoleh model PBL Geogebra lebih baik dari siswa yang memperoleh model PBL. 5) Kemandirian belajar siswa yang memperoleh model PBL Geogebra lebih baik dari siswa yang memperoleh pembelajaran konvensional .6) Terdapat korelasi positif antara peningkatan kemampuan pemahaman matematis dengan kemandirian belajar. 7) Aktifitas siswa yang mempeoleh model PBL menggunakan Geogebra rata-rata meningkat dari kriteria cukup menjadi baik, dan pembelajaran model PBL Geogebra lebih baik dari konvensional. Dengan demikian, pengembangan pembelajaran dengan metode geogebra ataupun Microsoft mathematic tidak lepas atau erat kaitannya dari sifat kemandirian dan kemampuan pemahaman matematis dalam penyelesaian masalah/persoalan di bidang matematika

Pendidikan Matematika FKIP Universitas
Palangkaraya.


(model Problem Based Learning) (Maryani, 2015) ${ }^{6}$.

Selain itu, berdasarkan Seminar Nasional Matematika di Universitas Negeri Semarang (UNNES) diketahui bahwa adanya diskusi dengan beberapa guru matematika di beberapa SMP Negeri dan Swasta di Semarang tentang pemanfaatan komputer yang sering diberikan dalam pembelajaran matematika hanya menggunakan aplikasi powerpoint. Namun demikian, tak jarang mereka lebih nyaman menggunakan papan tulis, terutama terkait dengan pembelajaran yang memerlukan ilustrasi grafik, guru jarang menggunakan komputer. Representasi grafik di papan tulis tentu saja bersifat statis, sehingga peranan sebuah parameter (koefisien) dari sebuah persamaan matematika tidak bisa dieksplorasi dengan bebas. Dengan demikian, akibatnya masih ada pengaruh koefisien tersebut terhadap grafik dari persamaan tadi sulit dipahami siswa. Tidak demikian halnya dengan grafik yang direpresentasikan dengan bantuan komputer. Grafik sajian komputer bisa sangat dinamik, perubahan pada suatu parameter dari suatu persamaan akan secara instant mengubah tampilan grafik dari persamaan tersebut. (Suweken, Mahayukti, \& Suarsana, 2013).

Perkembangan teknologi yang semakin hari semakin berkembang membuat pembelajaran matematika juga berkembang. Salah satu teknologi yang dapat dimanfaatkan di dunia sekolah

\footnotetext{
${ }^{6}$ Ely Maryani. (2016). Meningkatkan Kemampuan Pemahaman Matematis melalui Model Problem Based Learning Menggunakan Software Geogebra dan Dampaknya Terhadap Kemandirian Belajar Siswa SMK. Universitas Pasundan
}

adalah teknologi komputer. Komputer dapat digunakan sebagai salah satu media pembelajaran yang efektif. Komputer saat ini telah didukung oleh berbagai macam software pendidikan untuk pembelajaran matematika, antara lain SPPS untuk aplikasi statistik, Maple, Matlab, GeoGebra, Microsoft Mathematic, dan lainlain. Paradigma pembelajaran matematika saat ini memang telah bergeser dari teacher center menjadi student center. Pembelajaran matematika saat ini diarahkan pada pembelajaran yang interaktif, pemecahan masalah, dan ekspolatif sehingga para siswa memiliki kemampuan berpikir tingkat tinggi. Software GeoGebra dan Microsoft Mathematic dua diantara software yang dirancang untuk itu. Software GeoGebra dan Microsoft Mathematic memiliki keunggulan dan kelemahan. Salah satu keunggulan dari kedua software ini yaitu bukan software komersial sehingga dapat diinstal dengan gratis.

Menurut Sa'ud (2011;182) 'Kemajuan teknologi informasi banyak membawa dampak positif bagi kemajuan dunia pendidikan dewasa ini, keunggulan yang ditawarkan bukan saja terletak pada faktor kecepatan untuk mendapatkan informasi namun juga fasilitas multimedia yang dapat membuat belajar lebih menarik, visual dan inteaktif'. Banyak objek matematika yang bersifat abstrak. Hal demikian sangat berpotensi akan memunculkan berbagai kesulitan mulai dari cara guru menjelaskan sampai siswa mempelajarinya dan memahaminya. Faktor demikian mendorong perlunya media pembelajaran yang dapat memberikan pengalaman visual, baik kepada gurunya maupun kepada siswa dalam berinteraksi dengan objek-objek yang bersifat abstrak. Pada pembelajaran matematika banyak teknologi yang dapat dimanfaatkan untuk 
mendukung pembelajaran, baik perangkat keras maupun perangkat lunak. Salah satu perangkat lunak yang cukup potensial dimanfaatkan adalah Geogebra. Geogebra merupakan salah satu software bantu yang cukup lengkap dan digunakan secara luas. Nama Geogebra merupakan kependekan dari Geometry (geometri) dan Algebra (aljabar). Meski dari sisi nama hanya merujuk geometri dan aljabar, aplikasi ini tidak hanya untuk kedua topik tersebut, tetapi juga mendukung banyak topik matematika di luar keduanya. Berikut ringkasan mengenai kerangka pemecahan masalah pembelajaran matematika dengan pengabdian dan solusi melalui transfer iptek disajikan pada Gambar 1.1:

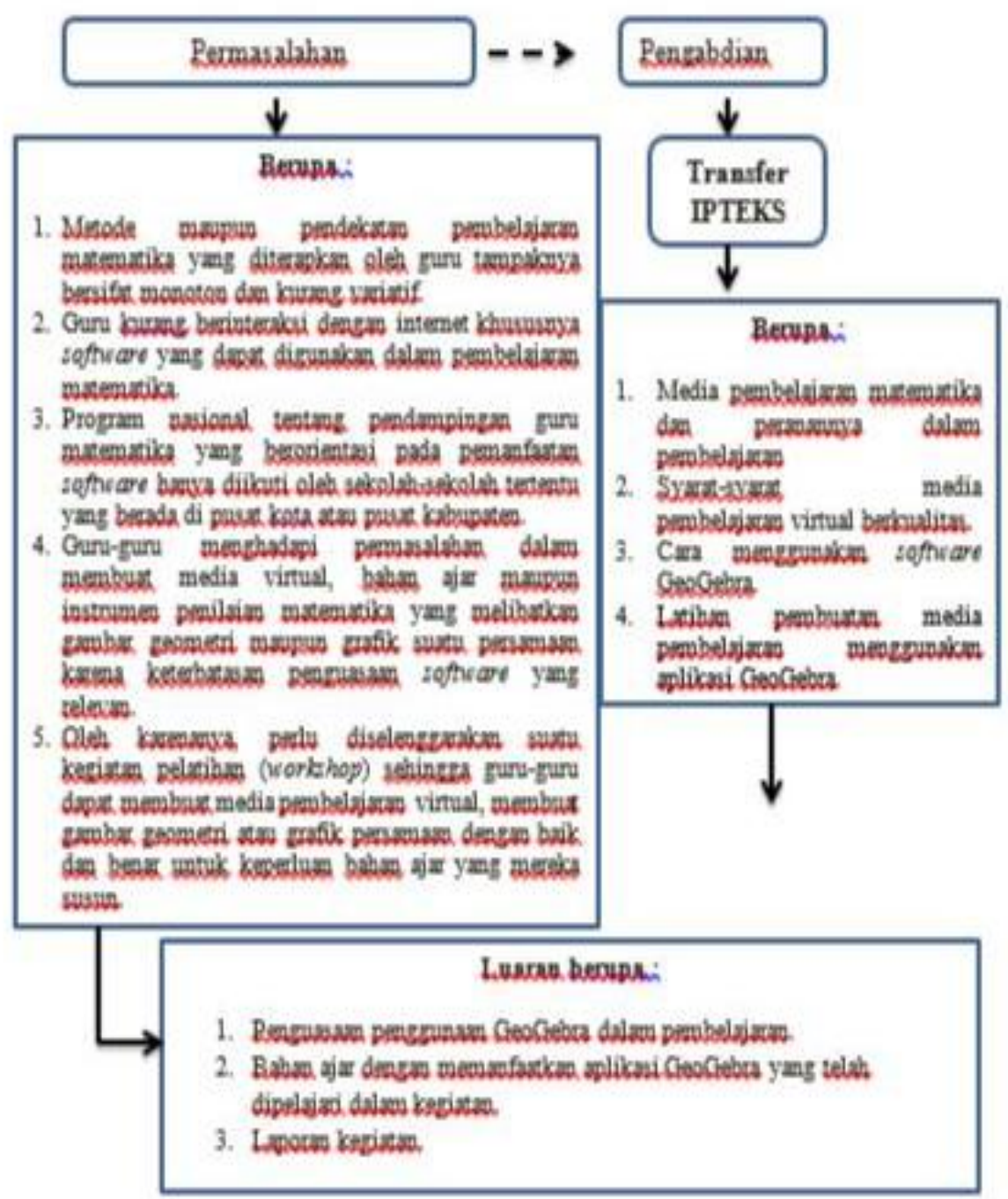

Gambar 1.1 Kerangka Solusi Pemecahan Masalah Sumber: Ary, dkk. 2018 
Selain faktor-faktor yang telah dijelaskan sebelumnya, faktor kemampuan awal matematika (KAM) siswa yang berbeda satu sama lainnya juga perlu diperhatikan. Hal tersebut menunjukan terjadinya perbedaan penerimaan materi masingmasing siswa, sehingga berakibat pula pada perbedaan hasil belajar mereka. Kemampuan awal matematika (KAM) akan berpengaruh pada pemahaman materi siswa berikutnya, karena matematika adalah mata pelajaran yang terorganisasikan, maka pembelajaran matematika harus dilakukan secara hirarki ${ }^{7}$.

Dengan demikian, adanya urgensi untuk melakukan penulisan yang berfokus pada pengembangan media pembelajaran berbasis teknologi dalam hal ini adalah yang diduga dapat meningkatkan pemahaman matematis yang berdampak pada kemandirian belajar dipandang oleh Penulis menjadi sangat utama. Berdasarkan latar belakang dan penelitian sebelumnya, peneliti tertarik melakukan penelitian mengenai pengembangan media pembelajaran matematika menggunakan geogebra dan Microsoft mathematic di salah satu sekolah percontohan yang mengutamakan computer science and technology sebagai satu dari sepuluh konsep life skills yang harus diasah dan dimiliki oleh setiap peserta didik yaitu di La Royba Islamic School. Dengan tujuan umum yaitu:

1. Untuk mengetahui infomasi tentang peningkatan kemampuan pemahaman matematis yang berdampak pada kemandirian belajar siswa melalui media pembelajaran Software Geogebra dan Microsoft mathematic di La Royba Islamic School

\footnotetext{
${ }^{7}$ ibid
}

\section{METODE PENELITIAN}

Metode penelitian yang digunakan adalah menggunakan wawancara mendalam (indepth interview) kepada setiap peserta didik yang menjadi sampel penelitian. Populasi dalam penelitian ini adalah sebanyak 30 siswa, yaitu seluruh siswa SMP dan SMA La Royba Islamic School tahun pelajaran 2017/2018, yang dalam pembelajaran di Sekolah sekaligus Pesantren ini menggunakan dua kurikulum, yaitu kurikulum life skills dan academic (kurikulum Dinas Pendidikan). Metode pembelajaran menggunakan dua software ini diharapkan dapat mengasah dan mengkombinasikan dua kurikulum bagi siswa.

Pemilihan sampel dilakukan dari populasi yang secara purposive (purposive sampling) 3 kelas dilakukan perlakuan dan wawancara, yaitu 1 kelas terdiri atas 11 siswa menggunakan Geogebra, 1 kelas terdiri atas 9 siswa menggunakan Microsoft math, dan 1 kelas lagi terdiri atas 7 siswa menggunakan pembelajaran konvensional. Instrumen yang digunakan dalam penelitian ini adalah instrument non tes berupa angket kemandirian belajar dengan lembar observasi, dan wawancara.

Waktu penelitian dilaksanakan selama satu semester dari bulan Januari hingga Mei 2018. Lokasi penelitian dilakukan di Pesantren Majelis Rahmatan Lil Alamin, La Royba Islamic School untuk tingkat SMP dan SMA, Depok. Peneliti yang merupakan guru matematika dan fisika di sekolah dan pesantren tersebut langsung melakukan observasi, wawancara, dan praktik aplikasi geogebra dan Microsoft mathematic. Panduan petunjuk dan penggunaan kedua aplikasi ini 
telah ada dalam penelitian sebelumnya diberikan kepada setiap siswa dan dipelajari siswa, kemudian setiap siswa wajib mempresentasikan hasil pembelajaran ke guru, termasuk kelebihan dan kekurangan dari pemakaian kedua aplikasi tersebut.

\section{HASIL DAN PEMBAHASAN}

\section{Pengertian software}

Software atau perangkat lunak adalah sekumpulan data elektronik yang disimpan dan diatur oleh komputer. Software ada berbagai macam jenisnya ada yang tidak berbayar dan berbayar. Pada pembelajaran matematika banyak macam software yang dapat digunakan antara lain:

- SPPS, merupakan software yang digunakan untuk menganalisis statistik antara lain median, modus, mean, simpangan baku, uji hipotesis, dan lainlain.

- GeoGebra, merupakan software yang digunakan untuk geometri, aljabar, dan kalkulus secara geometri.

- Microsoft Mathematic, merupakan software yang dapat digunakan untuk soal-soal aritmatika, matriks, statistik, aljabar linear, trigonometri bahkan beberapa persoalan yang melibatkan rumus fisika dan kimia. Software GeoGebra dan Microsoft Mathematic merupakan software yang dapat kita download gratis ${ }^{8}$.

\footnotetext{
${ }^{8}$ Aminah Ekawati (2016). Penggunaan Software Geogebra dan Microsoft Mathematic dalam Pembelajaran Matetamatika. Jurnal Pendidikan Matematika Vol. 2, No. 3, September-Desember 2016. STKIP PGRI Banjarmasin.
}

\section{GeoGebra}

\section{a. Program GeoGebra}

GeoGebra merupakan salah satu software yang dapat digunakan dalam menunjang pembelajaran matematika. GeoGebra dikembangkan oleh Markus Hohenwarter dari Universitas Florida Atlantik Amerika tahun 2001. GeoGebra sebagai software matematika dinamis yang dapat digunakan sebagai media pembelajaran matematika. Markus menggunakan software ini utuk membantunya dalam proses belajar mengajar matematika di Sekolah. GeoGebra adalah software dengan ide dasar menggabung geometri, aljabar dan kalkulus yang dapat digunakan untuk belajar dan mengajar di tingkat SD, SMP, SMA, dan Universitas (Hohenwarter, 2008). GeoGebra merupakan software yang kompetibel hampir di semua sistem operasi, dengan syarat pada computer yang dilakukan pengoperasian aplikasi ini telah menginstal java. GeoGebra dapat diinstal dengan bebas dan tidak berbayar dengan cara mengunjungi situs/websitenya ${ }^{9}$. Selain itu, hal ini sangat penting bagi guru, karena GeoGebra menawarkan kesempatan yang efektif untuk mengkreasi lingkungan belajar online interaktif yang memungkinkan siswa mengeksplorasi berbagai konsep-konsep matematika (Hohenwarter, 2008).

Menurut Mahmudi dalam Waluyo (2016) pemanfaatan program GeoGebra memberikan beberapa keuntungan, diantaranya adalah sebagai berikut:

1. Lukisan-lukisan geometri yang biasa-nya dihasilkan dengan cepat dan teliti dibandingkan dengan menggunakan pensil, penggaris, atau jangka.

\footnotetext{
${ }^{9}$ ibid
} 
2. Adanya fasilitas animasi dan gerakan-gerakan manipulasi (dragging) pada program GeoGebra dapat memberikan pengalaman visual yang lebih jelas kepada siswa dalam memahami konsep geometri.

3. Dapat dimanfaatkan sebagai balikan/ evaluasi untuk memastikan bahwa lukisan yang telah dibuat benar. 4 . Mempermudah guru/siswa untuk menyelidiki atau menunjukkan sifatsifat yang berlaku pada suatu objek geometri.

Secara umum ada tiga bagian utama dari tampilan software GeoGebra yaitu input bar, tampilan aljabar, dan tampilan grafik. Input bar untuk membuat objek, persamaan, dan fungsi baru yang akan ditampilkan. Tampilan aljabar digunakan untuk menampilkan dan mengedit semua objek dan fungsi yang dibuat. Tampilan grafik digunakan untuk menampilkan dan mengedit objek dan grafik dari suatu fungsi.

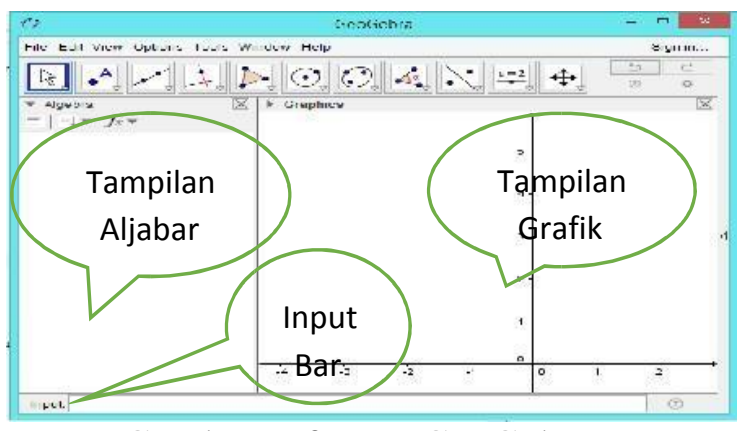

Gambar software GeoGebra

Menu utama pada GeoGebra terdiri atas File yang berfungsi untuk membuka, menutup, menyimpan, membagi, mengekspor file, dan memprint; Edit yang berfungsi untuk mengedit gambar; View yang berfungsi untuk mengedit tampilan; Options yang berfungsi untuk mengatur fitur tampilan; Window untuk membuka jendela baru; dan Help digunakan untuk membantu jika kesulitan dalam menjalankan GeoGebra. Selanjutnya pada tampilan GeoGebra ada alat konstruksi yang berguna untuk membuat fungsi, persamaan yang akan kita buat, berikut alat konstruksi pada GeoGebra:

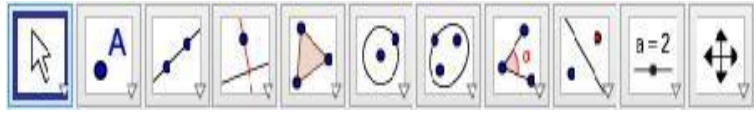

Gambar alat konstruksi GeoGebra

\section{Microsoft Math 4.0}

\section{a. Program Microsoft Math 4.0}

Microsoft Math merupakan sofware yang dibuat untuk sistem operasi Microsoft windows. Microsoft Math disediakan gratis oleh microsoft Corporation. Microsoft Math dirancang seperti kalkulator namun memiliki fitur lebih lengkap dan memiliki kemampuan menjabarkan langkah demi langkah penyelesaian. Microsoft Math dapat digunakan untuk siswa sebagai media pembelajaran untuk memahami matematika. Fitur dari Microsoft Math adalah: Panduan dalam menyelesaikan perhitungan secara langkah demi langkah dan interaktif. Graphing calculator dapat mengatur tampilan datanya dalam 2 dimensi maupun 3 dimensi yang berwarna. Dilengkapi dengan database rumus penting hingga lebih dari 100 rumus yang sering digunakan dalam perhitungan. Mempunyai banyak metode penyelesaian yang membantu menyelesaikan perhitungan dengan cepat. Memiliki unit Conversion Tool yang lengkap meliputi panjang, luas, volume, berat, temperatur, tekanan, energi, daya, kecepatan, waktu, dan masih banyak lagi. (Hernawati, 2012). 


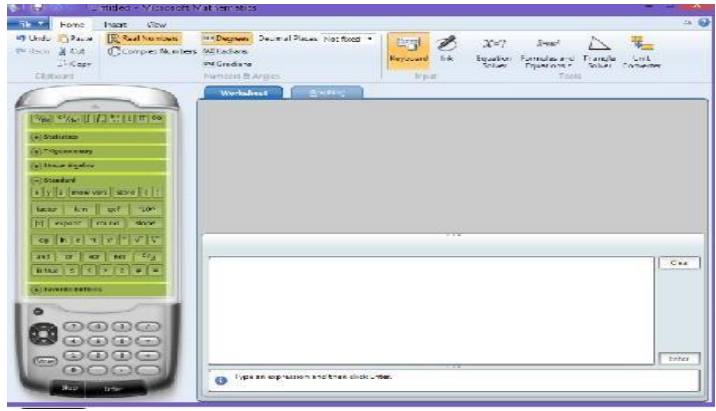

Gambar dari Microsoft Math 4.0

\section{b. Mengunakan aplikasi Microsoft Math 4.0}

Berikut akan disajikan beberapa contoh pemanfaatan software microsoft Math 4.0 dalam pembelajaran matematika di sekolah.

\section{- Materi aljabar di SMP}

Siswa dapat menggunakan aplikasi ini untuk mengecek jawaban mereka apakah sudah benar penyelesaiannya atau belum dengan memanfaatkan Equation Solver. Contoh, siswa diminta menentukan penyelesaian dari $2 x+3 y=6$, maka siswa tinggal mengklik tombol Equation solver, kemudian memilih solve a system of 2 equations tulis persamaan 1 pada bar equation 1 dan persamaan 2 pada equation 2 selanjutnya mengklik solve untuk memperoleh penyelesaiannya. Berikut tampilan pada Microsoft Math $4.0^{10}$ :

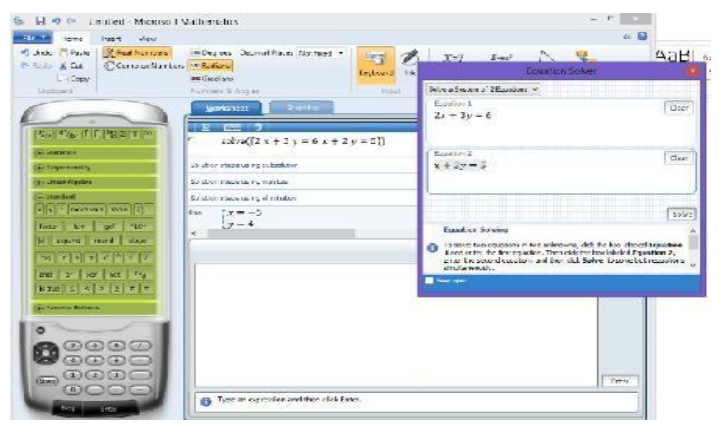

Gambar Microsoft Math 4.0
- Materi Persamaan Kuadrat di SMA

Siswa dapat menggunakan aplikasi ini untuk materi persamaan kuadrat $y=$ $a x^{2}+b+c$ untuk mengetahui pengaruh nilai a dan c. Pembelajaran dimulai dengan tahapan sebagai berikut:

a. Membuat grafik $y=a x^{2}+b+c$ pada microsoft math 4.0 dengan menggunakan fitur Graphing Calculator.

b. Caranya tulis persamaan kuadrat pada equations and functions

c. kemudian pilih enter dan graph. Pada Graph Controls, atur animate pada nilai a, b, dan c untuk mengetahui batas atas dan bawah nilai tersebut. Misalnya batas bawah -2 dan batas atas 2 maka mengklik angka -2 dan 2 pada animate.

d. Siswa dapat melihat perubahan yang terjadi jika a positif atau negatif.

e. Siswa dapat melihat perubahan yang terjadi jika c nol,c positif atau negatif. Pada tampilan sebagai berikut:

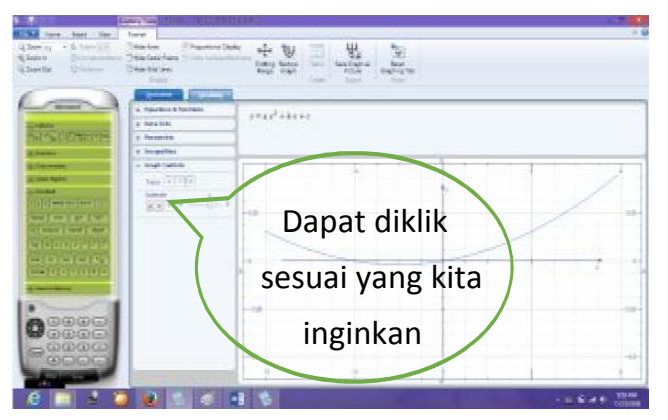

Gambar c nol,c positif atau negatif

\section{Hasil Penelitian dan Pembahasan}

\section{A. Hasil Observasi Aktivitas siswa}

Observasi dilakukan untuk mengamati penilaian aktivitas siswa selama proses pembelajaran dengan menggunakan dua aplikasi geogebra dan Microsoft math dalam penyelesaian matematika. Observasi dilakukan kepa- 
da kelas eksperimen. Bulan Januari sebanyak 4 kali pertemuan untuk perkenalan tentang kedua software ini. Bulan Februari sebanyak 4 kali pertemuan digunakan untuk praktik mandiri kedua software. Bulan Maret-April sebanyak 8 kali pertemuan untuk praktik secara kelompok dan dipresentasikan dihadapan guru. Kategori penilaian observasi terdiri dari $1=$ Sangat kurang, $2=$ Kurang, $3=$ Cukup, $4=$ Baik, $5=$ Sangat baik. Berdasarkan hasil penelitian diketahui bahwa dalam kegiatan pendahuluan atau pengenalan software diperoleh bahwa rata-rata aktivitas siswa naik dari 2,8 (cukup) menjadi 4,2 (baik), pada kegiatan inti (praktik individu mandiri) rata-ratanya naik dari 3,0 (baik) menjadi 4,6 (baik), dan pada kegiaan penutup (presentasi kelompok) rata-ratanya juga naik dari 2,3 (kurang) menjadi 4,7 (baik). Secara keseluruhan aktivitas siswa dalam mengikuti proses pembelajaran rata-ratanya naik dari 3,0 (cukup) sampai 4,3 (baik).
Berdasarkan data hasil penelitian tersebut diketahui bahwa aktivitas siswa yang menggunakan software geogebra dan Microsoft math dari bulan Januari hinggal April (satu semester) mengalami perubahan ke arah sikap yang lebih baik. Perubahan ini dimulai dari sikap siswa yang cukup, cukup, baik, baik, baik dan baik terhadap pengembangan media pembelajaran matematika menggunakan software geogebra dan Microsoft math.

\section{B. Hasil Wawancara}

Peneliti melakukan wawancara kepada siswa untuk menggali kemungkinan adanya permasalahan yang saat pembelajaran ditemui siswa pada pembelajaran yang berkaitan dengan penggunaan kedua software, dibandingkan pembelajaran konvensional .Wawancara dilakukan terhadap 3 siswa unggul dan 3 siswa asor yang mewakili kelas eksperimen menggunakan kedua software.Berikut hasil wawancara tersebut disajikan pada Tabel 4.1:

\section{Tabel 4.1 Interpretasi Jawaban siswa Terhadap Hasil Wawancara}

\begin{tabular}{|c|c|c|}
\hline No & Pertanyaan & Jawaban Siswa \\
\hline 1 & $\begin{array}{l}\text { Bagaimana pendapat } \\
\text { anda pembelajaran } \\
\text { dengan menggunakan } \\
\text { software geogebra dan } \\
\text { Microsoft math? }\end{array}$ & $\begin{array}{l}\text { a. saya sangat suka karena belajar pembuatan bangun ruang } \\
\text { dengan Geogebra memudahkan untuk paham dan tidak } \\
\text { membosankan walau pelajarannya rumit. } \\
\text { b. Microsoft math sangat membantu saat saya mengerjakan } \\
\text { persoalan yang berkaitan dengan transformasi linier atau } \\
\text { persamaan dan pertidaksamaan garis/linier } \\
\text { c. sangat senang karena tidak membosankan dan menarik untuk } \\
\text { dipelajari } \\
\text { d. sangat senang karena rumus pada transformasi, rumus dalam } \\
\text { fisika, konversi, memasukkan persoalan ke dalam aplikasi } \\
\text { dengan penyelesaian yang spesifik menjadi lebih mudah } \\
\text { dipahami } \\
\text { e. sangat memudahkan untuk memahami pelajaran matematika } \\
\text { dan membuat suasana belajar yang beda, menarik, dan efektif }\end{array}$ \\
\hline 2 & $\begin{array}{lr}\text { Bagaimana manfaat } \\
\text { fasilitas atau fitur yang } \\
\text { ada pada kedua } \\
\text { software ini? }\end{array}$ & $\begin{array}{l}\text { a. saya memanfaatkan fasilitas atau fitur yang ada pada kedua } \\
\text { software ini untuk menyelesaikan soal soal atau bahkan } \\
\text { membuat soal sendiri } \\
\text { b. dengan cara berlatih mengerjakan soal soal menggunakan } \\
\text { Geogebra dan Microsoft math }\end{array}$ \\
\hline
\end{tabular}




\begin{tabular}{|c|c|c|}
\hline & & $\begin{array}{l}\text { c. agar ketrampilan menggunakan kedua aplikasi ini lebih } \\
\text { berkembang } \\
\text { d. mempermudah cara belajar dan bisa memahami lebih cepat dan } \\
\text { jawaban tepat }\end{array}$ \\
\hline 3 & $\begin{array}{l}\text { Fasilitas atau fitur apa } \\
\text { yang ada pada kedua } \\
\text { software yang paling } \\
\text { disukai? }\end{array}$ & $\begin{array}{l}\text { a. menggambar grafik } \\
\text { b. penyelesaian persamaan linier dan tidak linier } \\
\text { c. menggeser geser suatu objek } \\
\text { d. membuat objek tiga dimensi/bangun ruang dan dapat } \\
\text { digerakkan dengan nyata } \\
\text { e. membuat segi banyak beraturan/ bangun datar } \\
\text { f. pemahaman trigonometri untuk SMA sangat baik dalam } \\
\text { menyelesaikan soal-soal } \\
\text { g. menentukan posisi objek secara tepat } \\
\text { h. menentukan bayangan suatu objek secara tepat }\end{array}$ \\
\hline 4 & $\begin{array}{l}\text { Dengan } \\
\text { pengembangan } \\
\text { pembelajaran } \\
\text { menggunakan kedua } \\
\text { software ini, apakah } \\
\text { kemampuan } \\
\text { pemahaman } \\
\text { matematika menjadi } \\
\text { lebih baik? }\end{array}$ & $\begin{array}{l}\text { a. dengan Geogebra tentang translasi,refleksi,rotasi lebih baik } \\
\text { dipahami lebi baik } \\
\text { b. dengan Microsoft math tentang trigonometri, persamaan linier } \\
\text { dan tidak linier, konversi, pembelajaran fisika dapat lebih baik } \\
\text { dipahami } \\
\text { c. Lebih memahami karena materinya lebih jelas dengan melihat } \\
\text { dari rumus dan panduan yang ada pada kedua software } \\
\text { d. belajar translasi, refleksi, rotasi dengan Geogebra tidak } \\
\text { membingungkan setiap siswa sehingga lebih paham dan jelas } \\
\text { e. belajar mengenai trigonometri, persamaan linier dan tidak } \\
\text { linier, konversi, pembelajaran fisika di bidang GLB dan GLBB } \\
\text { tidak membingungkan setiap siswa, sehingga lebih paham dan } \\
\text { jelas }\end{array}$ \\
\hline 5 & $\begin{array}{l}\text { Apakah dengan } \\
\text { kemampuan } \\
\text { pemahaman } \\
\text { matematika yang lebih } \\
\text { baik berdampak pada } \\
\text { kemandirian dalam } \\
\text { belajar? }\end{array}$ & $\begin{array}{l}\text { a. sangat berdampak baik karena menyelesaikan soal soal di } \\
\text { bidang matematika menjadi lebih mudah tidak perlu banyak } \\
\text { bertanya, lebih mengasah kemampuan analisis setiap siswa } \\
\text { secara mandiri } \\
\text { b. sangat berdampak karena menjadi lebih mudah dan dipahami } \\
\text { c. lebih percaya diri dalam mengerjakan latihan soal dan bahkan } \\
\text { membuat kreasi soal sendiir }\end{array}$ \\
\hline 6. & $\begin{array}{l}\text { Apa kelebihan dan } \\
\text { kekurangan dengan } \\
\text { pembelajaran } \\
\text { menggunakan kedua } \\
\text { software ini? }\end{array}$ & $\begin{array}{l}\text { a. Kelebihannya : dapat langsung praktek dan memahami panduan } \\
\text { yang ada } \\
\text { kekurangannya : harus punya laptop dengan pendukung java } \\
\text { dan memerlukan waktu pemahaman yang baik untuk setiap } \\
\text { fasilitas yang diberikan oleh software } \\
\text { b. kelebihan : sangat praktis dan mudah dipahami } \\
\text { kekurangannya : harus bisa mengoperasikan komputer dan } \\
\text { memahami fasilitas yang juga disesuaikan dalam kompetensi } \\
\text { dasar untuk setiap indikator pencapaian yang ada dalam RPP } \\
\text { siswa. }\end{array}$ \\
\hline 7. & $\begin{array}{l}\text { Apa sarannya terhadap } \\
\text { pembelajaran dengan } \\
\text { kedua software ini }\end{array}$ & $\begin{array}{l}\text { a. perbanyak materi tentang fisika pada Microsoft math, karena } \\
\text { fisika juga merupakan cabang dari matematika, seperti } \\
\text { pemahaman tentang kalor } \\
\text { b. siswa dalam kelompok harus paham tentang materi yang ada } \\
\text { dalam software }\end{array}$ \\
\hline
\end{tabular}


c. sebaiknya software ini dipisahkan lebih spesifik, mana materi yang harus dipelajari di tingkat SMP dan SMA, sehingga dapat dipelajari lebih mudah.

\section{KESIMPULAN}

Software GeoGebra dan Microsoft Math 4.0 dapat digunakan sebagai media pembelajaran dalam matematika. Kedua Software ini dapat diunduh secara gratis sehingga mudah kita mendapatkannya. Berdasarkan penelitian ini, maka aktivitas siswa yang menggunakan software geogebra dan Microsoft math mengalami perubahan ke arah sikap yang lebih baik. Perubahan ini dimulai dari sikap siswa yang cukup, cukup, baik, baik,baik dan baik terhadap pengembangan media pembelajaran matematika menggunakan software geogebra dan Microsoft math.

Selain itu, dengan adanya fitur-fitur dan kemudahan aplikasi yang ada di kedua software ini dapat membantu guru dalam menyampaikan materi pembelajaran, sehingga siswa dapat terlibat aktif secara mandiri serta menjadikan pembelajaran lebih kreatif, efektif dan bermakna. Kreatifitas yang diasah kepada siswa kemungkinan juga meningkatkan daya kreativitas siswa dengan pemahman matematis yang dapat membuat sendiri penyelesaian permasalahan sesuai dengan keinginan siswa. Kedua software ini memiliki manfaat khusus denganGeoGebra menekankan pada Geometri sedangkan Microsoft Math pada Aljabar atau persamaan garis/linier.

\section{REFERENSI}

Baltaci, S. \& Yildiz, A. (2015). GeoGebra 3D from the perspectives of elementary pre-service mathematics teachers who are familiar with a number of software programs. Cypriot Journal of Educational Sciences, 10(1), 12-17. Turkey.

Daryanto, Muljo Raharjo. (2012). Model Pembelajaran. Yogyakarta: Gava Media.

Eugen Ljajko. 2013. Development of ideas in a GeoGebra - aided mathematics instruction. University of Pristina, Kosovska Mitrovica, Serbia.

Ekawati, Aminah (2016). Penggunaan Software Geogebra dan Microsoft Mathematic dalam Pembelajaran Matetamatika. Jurnal Pendidikan Matematika Vol. 2, No. 3, SeptemberDesember 2016. STKIP PGRI Banjarmasin.

Maryani, Ely. (2016). Meningkatkan Kemampuan Pemahaman Matematis melalui Model Problem Based Learning Menggunakan Software Geogebra dan Dampaknya Terhadap Kemandirian Belajar Siswa SMK. Universitas Pasundan.

Pasini Mairing, Jackson (2013). Pembelajaran dengan Komputer: Dua Sisi Mata Uang. Makalah dalam Seminar Nasional Matematika dan Pendidikan Matematika FMIPA UNY. 
Prodi Pendidikan Matematika FKIP Universitas Palangkaraya.

Roberts, Nicky. 2016. Changes in the mLearning Configuration of a Secondary School Mathematics Service: The Case of Microsoft Math (South Africa) from 2008-2015. University of Johannesburg.

Sik Choy, Keong. 2010. Motivating Students in Learning Mathematis with Geogebra. Anelia Seria Informatica vol VIII fasc. 2-2010. Seoul National University, Seoul, Korea.

S. Anggoro. (2015). Pengembangan Modul Matematika Dengan Strategi Problem Solving untuk Mengukur Tingkat Kemampuan Berpikir Kreatif
Matematis Siswa. Al-Jabar: Jurnal Pendidikan Matematika.

Yuliasari, E. (2017). Eksperimentasi Model PBL dan Model GDL Terhadap Kemampuan Pemecahan Masalah Matematis Ditinjau dari Kemandirian Belajar. JIPM (Jurnal Ilmiah Pendidikan Matematika) .

Zahid, M. Zuhair., Dian Tri Wiyanti, Ary Woro Kurniasih. (2018).

Visualisasi Konsep Matematika dalam Pembelajaran Menggunakan Geogebra. Prisma: Prosiding Seminar Nasional Matematika; FMIPA. Universitas Negeri Semarang. 